\title{
Endoscope Distal Attachment Cap
}

National Cancer Institute

\section{Source}

National Cancer Institute. Endoscope Distal Attachment Cap. NCI Thesaurus. Code C157256.

A transparent cap for the end of an endoscope designed to maintain a constant distance between the endoscope and the mucosa to increase the detection of visible lesions. 